\title{
Hailuodon kansantarinat
}

Kerättyäni yli puolenkymmenen vuoden ajan (1948-54) tarinoita, kertomuksia ym. kansanperinnettä Hailuodosta alkoi jo kenttätyön aikana ilmaantua merkkejä näiden aiheiden ryhmittymisestä eräänlaisiin aluejakoihin. Muokatessani sitten aineistoa tulivat nuo keskittymät yhä kiinteämmiksi. Kullekin tarina-alueelle sijoittui varsinainen pääkertomus, jota ympäröivät muut suurin piirtein samansävyiset tarut. Tämä kaikki ei kuitenkaan tarkoita sitä, ettei silti olisi pienehköä määrää sellaisia yleistarinoita, joita tapaa kaikilla näillä alueilla, hajaantuneena yli koko saaren.

Eritellessäni näitä asioita kartoitusmittausteni ja maastotutkimusteni yhteydessä huomasin niiden herkästi liittyvän myös maisemaan; ne ikään kuin myötäilivät maaston muotoja sitä mukaa kuin tutkimusmittaukseni edistyivät.

Hailuotolaisten tarinoiden analysoiminen on vielä kesken, mutta kuitenkin jo siksi selväpiirteinen, että tarujen ekologisesta ryhmittymisestä voidaan laatia osapuinen karttakuvaus. Oheiseen piirrokseen on merkitty nämä tarina-alueiden karttakurat, joita on yhdeksän.

\section{Fruu Faarestiinan alue (F)}

Alueen päätaruna on hyvän haltijattaren, Fruu Faarestiinan oma syntytarina. Hailuodon vesille on vuosisatojen kuluessa haaksirikkoutunut useita laivoja, niin myös Santosen vesille. Taru kertoo, että joskus kauan sitten viskasi ankara syysmyrsky ison purjelaivan Lammasperään, aivan liki Vaskea. Yksikään ei pelastunut. Aallot olivat sitten kantaneet kapteenin vaimon ruumiin rantaan nykyisen Havanan maapalan kohdalle; henki otti asuinsijakseen rannalla olevan haavikon. Näin alkoi kapteenskan, hyvän haltijattaren, Fruu Faare- 


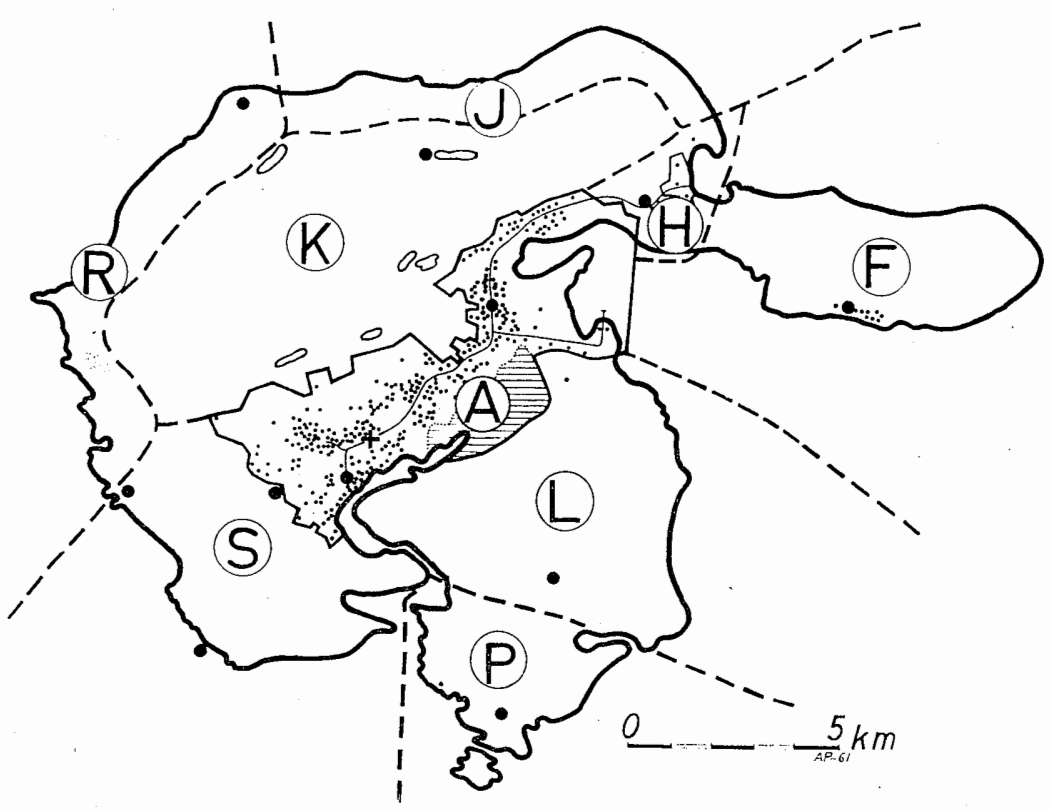

Hailuodon tarinaryhmitysalueet

Kirjaimet viittaavat telistissä mainittuilin selvityksiin. Mustat isot pisteet osoittavat päätarujen tapahtumiskohtia tarina-alueilla, pienet pisteet kyläalueiden asuttuja taloja eli savuja. Vahvat katkoviivat osoittavat tarina-alueiden jakovälejä. A-alue on kuvattu yhtenäisellä viivalla.

stiinan ilmestyminen aika ajoin kalastajille. Santosesta ja sen pintavista vesialueista tuli hänen valtakuntansa.

Santosen hyvä haltijatar syntyi kalastajien hyväntekijäksi, sillä se neuvoi heille - useimmiten unessa ilmestyen - milloin kala oli tulossa ja mistä sitä kulloinkin sai. Niinpä oli Tuohimaan Heikki kerran ollut yötä Huikun kalasaunalla, kun Fruu Faarestiina oli herättänyt hänet ja sanoi: "Mee vettään nuottaa Ulkolaian perukkaan!" Heikki oli mennyt, ja kalaa oli tullut niin kosolti, ettei keisarikaan olisi paremmin saanut. Samalla mökillä oli haltijatar tullut kerran yöllä Virpin Sofian luo ja istuutunut siihen hänen viereensä. kutrit hajallaan. Eikä Sofia ollut yhtään pelännyt.

Kaikki kokoamani Faarestiina-tarinat osoittavat, että tämä haltijatar on ollut ja on edelleenkin pääasiallisesti kalamiehiä varten. On vain ykssi toisinto, jossa Fruu Farestiina on ilmestynyt nukkujalle 
ja neuvonut maalla sijaitsevaan kohteeseen, aarteen etsimiseen siitä ja siitä.

Fruu Faarestiinan toiminta-alueena voidaan pitää koko sitä seutua, joka sisältyy oheisessa piirrolksessa F-kirjaimella merkittyyn karttakuvaan. Santosen vedet antavat arvokalaa, kuten siikaa, silakkaa ja maivaa. Santonen ja sen vesialueet ovat alati olleet hailuotolaisten lempialuetta. Kaukaisenakin paikkana se on ollut heille läheinen. Vuonna 1896 perustettiin Santosen talvikalastajien yhteenliittymä, minkä jälkeen, nuotta-apajien arpomisen tultua käytäntöön, tarvittiin myös entistä enemmän hyvää onnea eli lähinnä juuri Fruu Faarestiinan oivallista apua. Näin ei Santosessa sitten ollut sijaa muille haltijoille, ei edes kummittelijoille eikä juuri muille tarinoillekaan. Fruu Faarestiina on aina pysynyt ainoana haltijana Santosessa ja Santosen kalavesillä.

\section{Luukkaan äijän alue (L)}

Tämän alueen eli suurin piirtein Hanhisen keskushenkilönä on Luukkaan äijä. Tarina kertoo, että kerran, parisataa vuotta sitten Luukkaan Olii ja hänen toverinsa, eräs Ojakylän mies, menivät kirkkoon. Heillä oli papinkymmenykset maksamatta. Kirkolla tuli ensimmäisenä heitä vastaan kappalainen ojentaen kättään heille. Ojakylän mies oli kuitenkin sanonut vain, että "kah, piru konnan kämmenelle!", eikä ollut suostunut antamaan kättä. Luukkaan Olli taas, sävyisä mies, oli tervehtinyt pappia. Tästäpä olikin ollut seurauksena, että Ollista oli tullut tyhjännäkijä, hullu. Sielunpaimen oli näet pilannut hänet kostoksi maksamattomista kymmenyksistään. Kappalaisena oli silloin Hailuodossa Alakeeni ${ }^{1}$.

Hulluksi tehity Luukkaan Olli hirtti lopulta itsensä. Hänet haudattiin Luukkaan taakse. Siellä hän ei kuitenkaan saanut lepoa ja rauhaa, vaan alkoi öisin kummitella siinä määrin, että hänet oli siirrettävä veden taakse Hanhiseen. Siellä hänet kuopattiin ylävälle paikalle, kankaaseen, jossa sai vihdoinkin täyden rauhan. Nykyään hänen leposijallaan on pienoinen kiviroukkio ${ }^{2}$.

1 Hailuodon kappalaisena oli vuosina 1736-1762 Michael Allgén. Hänet pantiin viimeksi mainittuma vuonna viralta. Kerrotaan, että mainittu kättelytapaus olisi liittynyt papin virasta erottamiseen.

2 Tämän kirjoittaja suoritti kaivauksen hautapaikalla. Vainajaa ei löytynyt, mutta maa oli kyllä ennen liikutettua. 
Yhä edelleenkin on tapana, kun ollaan luukaslaisten (vaikkka tämän päivän Luukkaan asukkaat eivät ole sukuakaan 1700-luvun Ollille) kanssa vihan käämissä, huudella heille:

\section{Muistele musta Luukas aikoja entisiä, kuinka isäs ittens myllyyn hirteen veti!}

Luukkaan Ollin kammottava loppu on luonut Hanhiseen oman värinsä. Niinpä Äijänhaudan ohitse vievällä tiellä, kapealla polulla Äijänkankaalla uskotaan kummittelevan. Sanotaan olevan pelottavaa astella myös siliä tiellä, joka haudan lähellä orkanee Härkäsäikkään päin Iljanan kalamökille, koska täällälkin on kummittelua.

Aivan lähellä Äijänhautaa, noin parinsadan metrin päässä siitä on vähäinen risuaukio, jota nimitetään Säkkipekanaukioksi. Tämä Pekka oli varas. Tarinan mukaan hänellä oli oma metsäniittynsä ja latonsa juuri tällä paikalla; jätteitä, jotka aivan hyvin saattavat olla juuri tästä niittypalasesta, onkin todettavissa sanotulla maalla. Pekalla oli tapana juosta öisin - joskus päivälläkin — varkaissa toisten heinämailla kantaen säkissään anastamiaan heiniä omaan latoonsa. Uskomusten mukaan hän lie varastellut muutakin kuin heinää, ainakin kylältä.

Varkaan selville saamiseksi pantiin sitten liikkeelle taitava tietäjä. Tämä punoi vauluja kannon päähän ja paukautteli kiiloja vitsasten rakoihin. Ensin ei tapahtunut mitään, mutta kun alettiin kiristellä nalkkeja yhä syvempään, niin jopa Pekka toi varastamansa tavarat ja heinät pois.

Pohjoispuolisella osaa Hanhista on polkuja, joiden nimet ovat kaksiselitteisiä, jopa hieman rivonsekaisia. Itään päin Äijänhaudasta on näet kuulu Laukankorpi, joka on ennen muinoin ollut kesäiltaisin nuorten kokoontumiskenttänä. Luukkaan äijän tarina on vetänyt nämäkin puolet hyvin osuvasti Hanhiseen.

Pikku pirujen alue (P)

Syökäri, nuorin Hailuodon entisistä saarista, on tätä pirujen pikkutarumaastoa.

Keskeisin tarinapaikka on Pirunaukio. Tällä vesiperäisellä ryti- 
seudulla on uskottu ennen muinoin kummitelleen melkoisesti; on alati nähity pikkuisia piruja. Vielä parikymmentä vuotta sitten oli eräs kertoja, Haapalan Aapeli, kohdannut siellä paholaisia. Muitakin pirujen esiintymispaikkkoja osoitetaan Syökärissä. Yksi tällainen on Kästämän niittysauna jonkin matkan päässä äsken mainitusta aukiosta. Sata vuotta sitten se oli viinakyökinä kylällä, mutta siirrettiin sitten Syökäriin niittysaunaksi. Ovea lähinnä olevassa alavuoteessa ei vieläkään kukaan halua nukkua, sillä siinä ei saa rauhaa. Tarina kertoo, että viime vuosisadalla hukkunut Hahdon Liisa siellä kummittelee.

Kaupin kalasaunassa, joka niin ikään sijaitsee lähellä Pirunaukiota, tiedetään pirujen ja muiden pahojen henkien mekastavan oikein iltikseen. Juho Kauppi, etevä tietäjä, tapasi ennen muinoin panna saunansa eteen pihtiin lihapalasia ja variksenvarpaita ajaakseen näin mekastajat pois, että saisi nukkua yöt rauhassa. Nykyisinkään yöpyjät eivät saa tässä saunassa lepoa. On kuin vedeltäisiin naukuvaa pohjanahkaa oven raossa edestakaisin läpi yön.

\section{Sekatarujen alue (S)}

Suninkarin ja kylän välissä oleva alava seutu on melkoisesti samantapaista maastoa kuin Syökäri. Pirut vain täältä puattuvat, karkeita Luukkaan äijän tarinoita ei liioin tunneta eikä ole haltijoitakaan. Mitään yhtenäistä tarinarunkoa ei ole havaittavissa, minkä vuoksi seutua ei ole voitu liittää muuhunkaan tarinaryhmitylzseen. Siksi sitä täytyy käsitellä erikseen.

Mustassatöyrässä, aivan lähcllä kyläaluetta, kerrotaan ennen muinoin asuneen korkean sotaherran, joka oli ehkä havoittuneena jäänyt joukoistaan. Hänen nimensä oli kenraali Nauke. Toisten kertoman mukaan hän olisi taas ollut Krimin sodan aikaisia englantilaisia.

Kaitalan Pertin metsätcaistalla kasvoi lähellä rantaa ennen muinoin verevä tarrimänty. Hän möi sen Anttolan Matille, joka löi tarrin haloiksi. Yöllä sitten ilmestyi Matille unessa raskaudentilassa oleva nuori nainen, joka sanoi hänelle: "Pahan työn oot tehny, kaksisataa ja puoli vuotta oon sen alla maannu!"

Tällaista pientä hajanaista aineistoa sisältävät Suninkarin alueen tarinat. Vaikkka tällä rannilkolla on kesäisin varsin vilkasta suurrysäpyyntiä aina kaukaisille ulkopauhoille saakka, tarinoita on niukasti. 
Haaksirikkojen ranta-alue $(R)$

Hailuodon länsiranta vastaa suoraan aavalle merelle. Se tapaa ulapan myrskyt täydessä voimassaan ja ottaa vastaan monet haaksirikot. Melkein poikkeuksetta tarinat käsittelevät tällaisia haakssirikkoja tai liittyvät jollakin muulla tavalla näihin tai näiden seuraamuksiin.

Alueen ydintarina kuvaa Sergein kummittelua Karvossa (nykyisessä Keskiniemessä). Vielälkään ei juuri kukaan yksinäinen eläjä voi Karvossa nukkua rauhassa - se on muuten koettu jo aikoja sitten. Mutta erikoisesti Kniivilän ja Annusen kalarannan osuudella on tällainen rauhattomuus ja kummittelu öisin ollut aina hyvin pelottavaa. Tarinan mukaan olisi joku ruumis haaksirikkoutuneesta laivasta ajelehtinut Karvon nantaan, ja tämä vainaja - Sergei nimeltään siellä nyt aiheuttaa epäjärjestystä öisillä esiintymisillään.

Marjaniemen Hannukseen kulkeutui ennen muinoin iso purjelaiva. Se oli tuomassa Tukholmasta Ouluun raskasta lastia, valtiopankin rahoja. Rantaan ajautuneet ruumiit korjattiin talteen, mutta minne painavat rahat joutuivat, siitä ei ole tietoa. Hannuksessa ne ovat jossakin hiekkaan vajonneina, ja ken uhraa yösydännä lunnaina valkealiinaharjaisen varsan ja valkotukkaisen poikalapsen, löytää tämän aarteen.

Tällaisia tarinoita on alueella viljalti. Milloin jauholastissa ollut laiva on hajonnut Kälminmatalalle niin tyystin, että koko mittava länsirannikko on ollut täynnä kaikenlaisia jauhosäłkejä. Milloin taas raskaassa tervakuormassa ollut laiva on pirstoutunut rannan kiviin, ja hailuotolaiset ovat sitten joutuneet pinomaan tervaisia ruumiita Juolan riiheen, jossa vainajat kummittelevat.

\section{Jättiläisen alue (J)}

Pohjoista rantaa on ammoisista ajoista alkaen sanottu takarannaksi. Se on alati ollut mitä parhainta heinämaata, Vesan ja Pökön niitityä. Pitkät vahtiaidat ovat vuosisatojen ajan erattaneet hyvät heinämaat joutomaasta, joka taas on kesäisin ollut hevosien ja lehmien sekä lampaiden ruokamaata. Siellä onkin ollut kesäisin hyvin vilkasta.

Sanotaan tänne joskus kauan sitten tulleen jättiläisen mantereelta. Tarkoin ei kuitenkaan tiedetä, tuliko hän suoraan Kurkun 
poikki Siikajoelta vai mutkitse Oulunselän kautta. Joka tapauksessa oli vettä ollut niin mittavasti, että jättiläisen kahlatessa meren ylitse oli tuppi viistänyt vettä. Hän oli asettunut takarannan vehmaille maille. Mutta pian hän oli huomannut paikan levottomakisi ja lähtenyt pois. Oli lähtiessään sanonut:

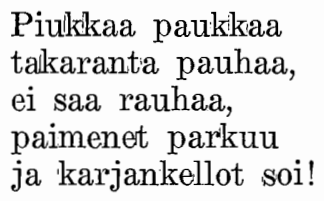

Helmi-röökynän alue (H)

Tämäkin alue on vain yhden tarun tienoota, Helmi-röökynän tarumaata. Helmi-röökynä istuu lujasti kivellä Ojakylästä Pottiin vievän metsätien varressa, on istunut jo vuosisatoja ja sukinut hajallaan olevaa tukkkaansa. Mitään muuta hän ei ole tehnyt eikä tee. Tämä haltijatar ei ole paha, mutta ei hän ole tehnyt varsinaisesti hyvääkään. Hän on ollut ikäänkuin vain Fruu Faarestiinan etuvahtina kuljettaessa Santoseen.

\section{Korpitarinoiden alue $(K)$}

Tämän metsäalueen pohjoisosassa sijaitseva Nuottajärvi on vedenjumalan Ahdin koti. On mielenkiintoista havaita, että se sijaitsee lähellä jättiläisen aluetta, ei kaukana Helmi-röökynän kivestä eikä varsin etäälï Fruu Faarestiinankaan alueesta. Kaikki nämä suuret henget asuvat lähekkäin. Ihmeellistä vain on, että vedenjumala on tungettu keskellä synkkkää metsää sijaitsevaan pieneen lietepohjaiseen järveen eikä aavaan mereen.

Tähän samaan yksinäiseen erämaajärveen on sijoitettu tarinan mukaan myös magneettikivi. Siellä se piilee veden alla jossakin ja imee kaiken liikkuvan puoleensa. Jolloinkin viime vuosisadalila tarttui tähän kiveen vene. Vasta miesvoimin se oli saatu kivestä inti.

Kumma yhteensattuma on, että juuri tässä jumalaisessa Nuottajärvessä vilisee sitkeähenkisiä ruutanoita; muualla Hailuodossa ei tiettävästi tätä kullanvälklkyvää kalaa ole.

Tähän Nuottajärven lietepohjaiseen. rantamaahan Rantti-äijä 
polki poilkansa kanssa Krimin sodan aikana ampumansa kirkasnappisen englantilaisen. Näitä englantilaisten ruumiita on tällä tarina-alueella painettu muihinkin suovesiin.

\section{Kylätarinoiden alue (A)}

Hailuodon tarujen luokittelussa ovat kylätarinain alueeksi muodostuneet paitsi varsinainen asutusseutu myös siihen välittömästi liittyvät viljelysmaat sekä Hanhisen vastainen Kirkonsalmi. Koko tämä tarina-alue on kuvattu karttapiirroksessa kirjaimella A.

Hailuodon kansantarinoiden ydin, niiden mehukkain sydän keskittyy juuri tähän asuttuun seutuun, keskelle saarta ja turvaan kaukaisista merenrannoista. Tarinakokoelma on ylen värikäs ja monipuolinen: aarrevalkeita, ruumisvihtoja ja vainajien jumalanpalveluksia, tyhjännäkijöitä, piruja ja kummittelijoita jne.

On vaikeata keksiä varsinaista päätarinaa tai -tarinoita. Voitaisiin kylläkin todeta päätarinat eri taruryhmille, mutta näitäkin olisi varsin hankkala aivan selväpiirteisesti eritellä toisistaan. Rajoitumme sen vuoksi tässä mainitsemaan vain pari kylätarinaa, jollaisia ei tapaa saaren muilta tarina-alueilta.

Kaitalan pirut eroavat Syökärin pikku paholaisista siinä suhteessa, että niitä on paljon ja että ne ovat kulussa koko ajan. Näiden pirujen nähdään kulkevan pitkin kujaa Kaitalan taloon. Alati niitä sinne lappaa tien täydeltä, mutta koskaan ei ole nähty niiden tulevan takaisin. Talon pajasta on sitä paitsi kuulunut jatkuvasti lapsen itkua.

Kerran oli sitten Kaitalan emäntä menossa hevosella kirkolle, kun eläin säikähti kujassa vastaantulevien pirujen joukkoa ja vauhkoontuneena viskkasi reen niin rajusti kujan aitaa vastaan, että emäntä ruhjoutui kuoliaaksi.

Ojakylän puolella taas on kuulun Franttin tervahaudan jäännös. Maantien ylitse hurauttelee tarkoin tässä paikassa aika ajoin pienoinen tynnyri edestaas. Tien ylitse vierähtelevästä astiasta kuuluu huuto:

Ota nippu nappulasta, kyllä minä itteni elätän!

Asukaslukuun ${ }^{3}$ verrattuna on Hailuodossa ennen muinoin elänyt

${ }^{3}$ Hailuodossa on ollut asukkaita seuraavasti: v. 1805 1129, v. 18101027 , v. 19012288 ja v. 19102325 . 
paljon tietäjiä, ehkä runsaammin kuin muualla. Lähes joka toisessa talossa on joskus asunut mahdikas tietäjä. On ollut sellaisia tekijöitä kuin Pertaan muori, Paakko-Teemu ja Kreus-Pekka, Sauvolan Anna ja Pasa-Matiti, Hornamon Juho, Muuvin Heikki ja Sääski-Taava ym. Väkevimpänä tietomiehenä pidetään kuitenkin Ilvesmeesaa, eikä vähäinen mahdiltaan ole ollut Pertaan muorilkaan, venymälangan tekijä.

En katso olevan aihetta nyt puuttua tämän enempää kylätarinoihin. Näitä on kosolti, mukana kaikkea sellaista, mikä luonnonmukaisesti kuuluu kansanperinteistä rilkkaaseen kyläelämään.

Olen edellä esittänyt vain vähäisen osan niistä lukuisista tarinoista, jotka valaisevat hailuotolaisten kansantarujen ekologiaa. Tarkkoja rajoja ei kuitenkaan voida piirtää alueiden välille. On ilmeistä, että välirajat seuraavat lähinnä luonnonmukaisia juonteita eli maisemallisesti juuri sellaisia kohtia, jotka ovat olleet ja ovat edelleenkin tarinallisesti mitään sanomattomia maastokuvioita.

Samalla kun tarinaryhmät vaihtuvat näillä rajamailla toisiksi, muuttuu myös maisema topografisestikin toisenlaiseksi. Hailuodon tarinaekologiaan ovat ilmeisesti vaikuttaneet

- maastolliset seikat,

- nautinta-alueelliset seikat ja

- alueelliset ikäseikat.

Vanhimpia ovat ilmeisesti karttapiirrokseen merkityt K- ja Atarina-alueet. Iäkkäitä ovat myös R- ja J-alueet, jotka ovat maannousun mukaisesti alati kuuluneet noihin ensin mainittuihin tarinaalueisiin. Sitten seuraavat nuoremmat alueet, lueteltuna ikäjärjestyksessä: L, H ja F. Kaikista nuorimmat - samalla tarinoista köyhimmät sekä risaisimmat — ovait $\mathrm{S}$ - ja $\mathrm{P}$-seudut.

Tarinoiden kertojista on tähän varsin suppeaan yleiskatsaukseen vaikea liittää täydellistä luetteloa, sillä haastateltavina ovat olleet kaikki hailuotolaiset, ja kaikilla heillä on myös ollut paljon tietoa annettavana. Mutta sittenkin on syytä mainita tässä muutamia suurtaitajia: Aatu ja Martta Järvelä, Viljo ja Fanni Heikkala, Heikki ja Hanna Sorto, Pauli Annunen, Heikki Valppu, Väinö Ruonala, Heikki Einari Sipilä, Vilho ja Nestori Hahto, Anna Hahto, Kustaa Rantasuomela ja Pertti Vähämetsä sekä Ahti Tausta. 
Näitä kansantarinoita kootessani totesin, että jos niissä oli havaittavana paikallistumista edellä esitetyllä tavalla, niin oli myös kertojissa huomattavana vastaavanlaista ryhmittymistä. Oli näet — vaikka kysymykssessä on vain noin $180 \mathrm{~km}^{2}$ :n laajuinen saari - kertojia, jotka sen sijaan, että olisivat itse tarinoineet jonkin toisen alueen muistoista, neuvoivat kääntymään niiden puoleen, jotka taitaisivat ne paremmin selostaa. Omasta tietoalastaan he taas kyllä halusivat ja osasivat kertoa vaikka millä mitalla.

\section{Ahti Paulaharju: Die Volkssagen von Hailuoto}

Vorliegende Untersuchung gründet sich auf eingehende topographische Kartierungen (Massstab 1:1000 und 1:10000), siedlungsgeschichtliche Geländeuntersuchungen und vom Verf. in den Jahden 1948-54 sowie mehrmals im Laufe der darauffolgenden Jahre an Ort und Stelle durchgeführte folkloristische Sammelarbeiten. Die jährliche Landhebung beträgt in Hailuoto etwa $9 \mathrm{~mm}$. Dadurch sind im Laufe der Jahrhunderte mehrere kleine Inselchen zu einer grossen Insel, dem heutigen Hailuoto, verschmolzen. Die kahlen Klippen wurden zu Bruchwaldinseln, woraus im Laufe der Zeit kiefermbewachsene Heiden entstanden. Der Schwerpunkt der Besiedlung lag seit jeher auf der Ostseite der am weitesten westwärts gelegenen Insel, d.l. im Zentrum des heutigen Hailuoto. Genauso wie die Insel heute durch Kartierung sozusagen in ihre ursprünglichen Bestandteile zerlegt werden kann, sind auch in den Volkssagen der Insel entsprechende örtliche Gruppierungen zu erkennen, indem die Grenzen der Motive der verschiedenen Gebiete einerseits der Richtung der ehemaligen Sunde und anderseits den verschiedenen Phasen der Landhebung folgen. Diese Grenzen können stellenweise, zunächst im östlichen Teil von Hailuoto, ziemlich deutlich nach der ehemaligen Gruppierung der Inseln festgelegt werden. Am West- und Nordufer der Insel verläuft die Grenze der obenerwähnten Gebiete kilometerweise längs der ehemaligen Uferlinie, von der ab, als die Landhebung ihren Fortgang nahm und die Insel grösser wurde, eine merkbare landschaftliche Stabilisierung eintrat.

Bei der Betrachtung verschiedener grundlegender Faktoren fällt auf, wie sich der Lebensrhythmus der Inselbewohner zusammen mit dem allgemeinen Fortschritt der Insel entwickelte; auf Grund dieses Rhythmus haben sich auch die Volkssagen den verschiedenen Teilen von Hailuoto angepasst. Trotz des Verschwindens der Sunde, der Verbreitung der Vegetation usw. während der Landhebung haben sich diese Sagen bis heute auf ihren eigenen Gebieten in mehr oder weniger ausgeprägter Gestalt erhalten.

Den wichtigsten Teil bilden die eigentlichen Dorfsagen (A). Den Nord- und Nordostgebieten der Insel eigen sind Sagen mit Riesen- oder Feenmotiven $(J, H, F)$. Die östlichen und südöstlichen Teile werden von Spukgeschichten beherrscht ( $L$ und $P$ ). Die Sagen der südlichen und westlichen Teile (S, R) behandeln vorwiegend Schiffbrüche und deren Folgen. Die grösste der ehemaligen Ur-Inseln ist das Gebiet typischer Waldsagen (K). 